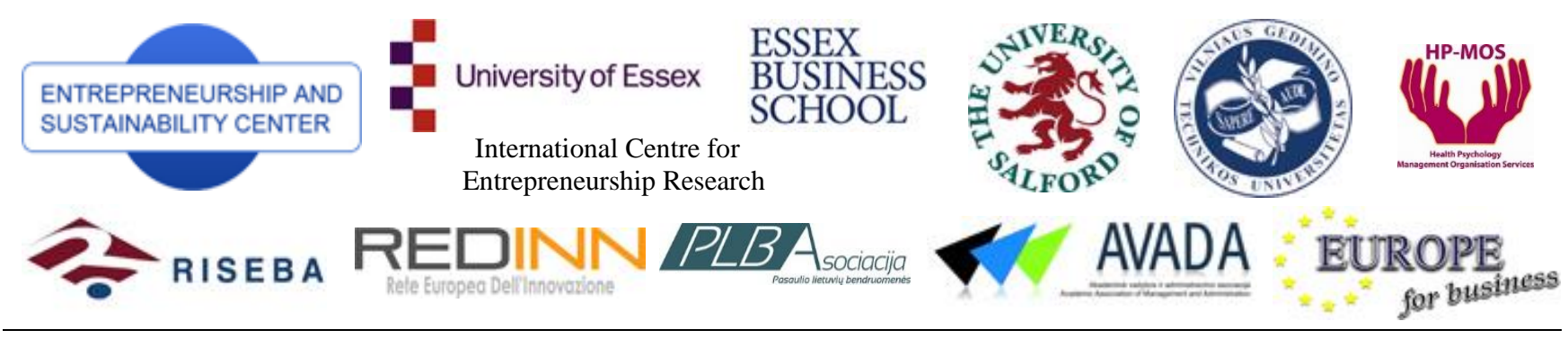

ENTREPRENEURSHIP AND SUSTAINABILITY ISSUES

ISSN 2345-0282 (online) http://jssidoi.org/jesi/aims-and-scope-of-research/

\title{
SUSTAINABLE RISK MANAGEMENT: FUZZY APPROACH TO VOLATILITY AND APPLICATION ON FTSE 100 INDEX
}

\author{
Sinem Peker ${ }^{1}$, Manuela Tvaronavičienė ${ }^{2}$ Bora Aktan ${ }^{3}$ \\ ${ }^{1}$ Yasar University, Department of Statistics, Üniversite Caddesi, No: 35-37, Ağaçlı Yol, Bornova, Izmir35100, Turkey; \\ ${ }^{2}$ Vilnius Gediminas Technical University, Sauletekio 11, 10223 Vilnius, Lithuania; \\ ${ }^{3}$ University of Bahrain, College of Business Administration, Department of Economics \& Finance, PO Box 32038 Isa Town, \\ Kingdom of Bahrain
}

Emails: 1sinem.peker@yasar.edu.tr; ${ }^{2 m a n u e l a . t v a r o n a v i c i e n e @ v g t u . l t ; ~}{ }^{3} g$ bora@uob.edu.bh

Received 18 May 2014; accepted 20 July 2014

\begin{abstract}
In this paper, a fuzzy volatility labeling algorithm is offered to detect the periods with abnormal activities on daily share returns. Considering the vagueness in the switches of the time periods, the membership functions of high and normal volatility classes are introduced. In the assignments, both the density structure and membership degree are used. It is believed that this algorithm may be helpful to construct different estimation models for the time periods with normal and abnormal activities. Authors offer algorithm, which can be used as a tool for sustainable risk management.
\end{abstract}

Keywords: volatility, FTSE, clustering, fuzzy number, labeling

Reference to this paper should be made as follows: Peker, S.; Tvaronavičienè, M.; Aktan, B. 2014. Sustainable risk management: fuzzy approach to volatility and application on FTSE 100 index, Entrepreneurship and Sustainability Issues 2(1): 30-36.

DOI: http://dx.doi.org/10.9770/jesi.2014.2.1(4)

JEL Classifications: C1, G00

\section{Introduction}

Investment into securities requires sustainable risk management technique, which is crucial for sustainable development of business and for overall process of sustainable entrepreneurship (Baikovs, Zariņš 2013; Šimelytė, Antanavičienè 2013; Wahl, Prause 2013; Laužikas, Krasauskas 2013; Laužikas, Mokšeckienė 2013; Litvaj, Poniščiaková 2014; Figurska 2014; Šabasevičienė, Grybaitė 2014; Dzemyda, Raudeliūnienė 2014; Tvaronavičienė 2014; Garškaitè-Milvydienè 2014). Time series clustering is a popular technique which is used in monitoring on brain activities, commercial consumption, retail pattern, gene expression, financial data, robot sensor data and so on (Zhang et al. 2011). It can be applied in varies fields with different purposes such as, the grouping of the time series of star brightness in the astronomy; the grouping of countries by considering their time series of gross national product (GNP) in the economy; the grouping of companies by taking into account their time series of returns in the finance; the segmenting of the markets by handling the consumption behavior of consumers during a time period in the marketing (D'urso and Maharaj 2009).

In the literature, there are many researches about the generation of time series clustering methods. For example, Zhang et al. (2011) suggested a novel algorithm for shape based time series clustering by using dynamic time 
warping distance function and hierarchical clustering algorithm. D'urso and Maharaj (2009) introduced a fuzzy clustering approach which is used the autocorrelation functions of time series. Maharaj and D'Urso (2011) proposed a fuzzy clustering approach for time series based on the estimated cepstrum which is the spectrum of the logarithm of the spectral density function. Rodpongpun et al. (2012) offered Selective Subsequence Time Series (SSTS) clustering which use data encoding to cluster only essential subsequences. Their technique automatically detects an appropriate number of clusters without user's intervention. Lai et al. (2010) put forward a novel twolevel clustering method which takes into account both the whole time series and the subsequence information of time series. Chen and Tanuwijaya (2011) developed a multivariate fuzzy forecasting method which includes automatic clustering technique to forecast the Taiwan Stock Exchange Capitalization Weighted Stock Index (TAIEX). Cheng et al. (2008) produced a novel multiple-attribute fuzzy time series method which includes a fuzzy clustering to partition datasets objectively and allows processing of multiple attributes. Bang and Lee (2011) suggested a hierarchical classification technique in which the cross-correlation clustering algorithm is merged with the k-means clustering algorithm (HCKA) to overcome the problem dealing with non-linear data. Liao (2007) proposed the exploratory mining of multivariate time series using partition-based clustering methods. D'urso et al. (2013) handled the clustering of financial time series, they used an autoregressive representation of GARCH models in the partitioning around medoids algorithm. Alaeddini et al. (2009) focused on control charts and change point estimation problem. They suggested clustering as a potential tool for change point estimation and proposed a novel hybrid approach based on the concepts of fuzzy clustering and statistical methods. Nasibov and Peker (2011) proposed a time series labeling algorithm based on fuzzy c-means and k-nearest neighborhood rule.

Among these researches, D'urso and Maharaj (2009) underlined the fact that time series has dynamic behavior over time and the switch from one time state to another is generally vague. So a fuzzy approach may be more appropriate in the evaluation of it. Considering this fact, in this paper, a fuzzy volatility labeling algorithm is offered. In the algorithm, the membership functions of high and normal volatility classes are constructed by taking into account the time series. Each trading day is assigned to one of the classes, considering maximum membership degree. The density of trading days with abnormal activities, $p$, is calculated. The $s$ trading days is handled and if the density of high activities in $s$ trading days is greater than $p$, this period is labeled as "the period with high volatility"; otherwise it is labeled as "the period with normal volatility". The last procedure is applied on each $s$ trading days.

\section{Preliminaries}

The Fuzzy Set Theory, which was firstly introduced by Zadeh (1965), is a very useful theory to handle vague and ambiguous problems, expressions of linguistic values and human subjective judgments of natural language (Cheng et al. 2008). To consider both vague and imprecise data, the characteristics of fuzzy sets allow a degree of membership to be associated with a value in a set (Bang and Lee 2011).

A fuzzy number $A$ is a fuzzy subset of the real line $\mathfrak{R}$ with the membership function $\mu_{A}$ which is normal, fuzzy convex, upper semi-continuous, supp $A$ is bounded, where supp $A=\operatorname{cl}\left\{x \in R: \mu_{A}(x)>0\right\}$ and $c l$ is closure operator (Ban 2008). Let $A_{\alpha}=\left\{x \in R: \mu_{A}(x) \geq \alpha\right\}, \alpha \in(0,1]$, denote an $\alpha$-cut of a fuzzy number $A$. Every $\alpha$-cut of a fuzzy number is a closed interval, i.e. $A_{\alpha}=\left[A_{L}(\alpha), A_{R}(\alpha)\right]$ where (Grzegorzewski 2008)

$$
\begin{aligned}
& A_{L}(\alpha)=\inf \left\{x \in \mathfrak{R}: \mu_{A}(x) \geq \alpha\right\} \\
& A_{R}(\alpha)=\sup \left\{x \in \mathfrak{R}: \mu_{A}(x) \geq \alpha\right\} .
\end{aligned}
$$

The most common membership functions are triangular, trapezoidal and Gaussian membership functions. They can be described by Eq.(3)-(5), respectively (Ang and Quek 2012; Lee and Pan 2009). 


$$
\begin{aligned}
& \mu_{A}\left(x ; a_{1}, a_{2}, a_{3}\right)= \begin{cases}0 & , \quad x \leq a_{1} \text { or } x \geq a_{3} \\
\frac{x-a_{1}}{a_{2}-a_{1}} & , \quad a_{1}<x \leq a_{2} \\
\frac{a_{3}-x}{a_{3}-a_{2}} & , \quad a_{2}<x<a_{3}\end{cases} \\
& \mu_{A}\left(x ; a_{1}, a_{2}, a_{3}, a_{4}\right)= \begin{cases}0 & , \quad x \leq a_{1} \text { or } x \geq a_{4} \\
\frac{x-a_{1}}{a_{2}-a_{1}} & , \quad a_{1}<x<a_{2} \\
1 & , \quad a_{2} \leq x \leq a_{3} \\
\frac{a_{4}-x}{a_{4}-a_{3}} & , \quad a_{3}<x<a_{4}\end{cases} \\
& \mu_{A}\left(x ; a_{1}, a_{2}, a_{3}, a_{4}\right)= \begin{cases}e^{\frac{-\left(x-a_{2}\right)^{2}}{2 a_{1}^{2}}} & , \quad x<a_{2} \\
1 & , \quad a_{2} \leq x \leq a_{4} \\
e^{\frac{-\left(x-a_{4}\right)^{2}}{2 a_{3}^{2}}} & , \quad x>a_{4}\end{cases}
\end{aligned}
$$

Their visual demonstrations are given in Figure 1.
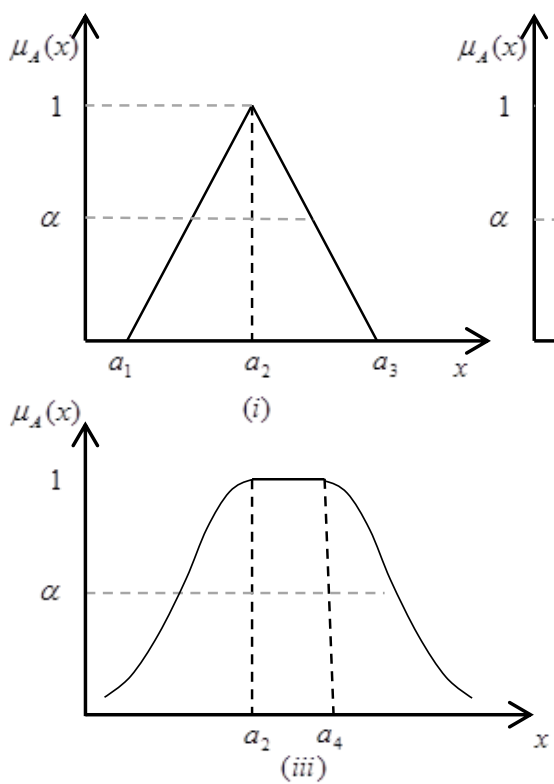

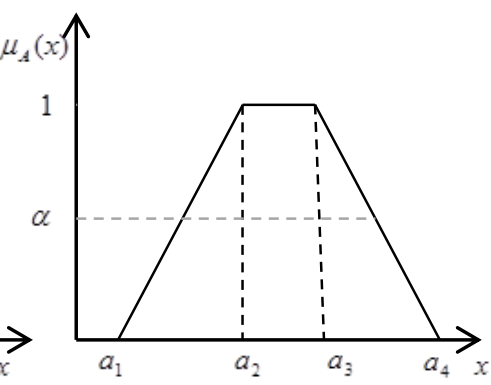

(ii)

Fig. 1. The triangular (i), trapezoidal (ii), Gaussian membership (iii) functions

Source: authors

\section{Fuzzy Volatility Labeling Algorithm (FVL)}

The offered algorithm is constructed to group daily share returns under the consideration of volatility. Considering the ambitious switches from one state to another state, the Gaussian membership functions of high and normal volatility classes are used. In the evaluations of membership functions, firstly, the daily share returns, $Y_{t}$, are separated into two groups. In one of the groups, the $Y_{t}$ values which have standardized values in the interval of [$2,2]$ are stored. These values are used in the evaluation of the membership function of normal volatility class. The remaining $Y_{t}$ values are stored in other group, and from them, the membership function of high volatility class is evaluated. In both membership function evaluations, the descriptive statistics of daily share returns are considered. 
After constructions of membership functions, each daily share return is reassigned to a class in which it has maximum membership degree. After all assignments, the density of high activities is calculated from whole time series. Then, the sub-periods of time series is handled, and the density of high activities of each sub-period is calculated. If the density of sub-period is greater than the density of whole time series, the sub-period is labeled as "the period with high volatility"; otherwise it is labeled as "the period with normal volatility".

\subsection{Algorithm}

Step 1: Calculate the daily share returns by Eq.(6),

$$
Y_{t}=\ln \left(\frac{p_{t}}{p_{t-1}}\right)
$$

Step 2: Obtain the standardized values of $Y_{t}$ by Eq.(7)

$$
Z=\frac{\left(Y_{t}-\bar{Y}_{t}\right)}{s_{D}}
$$

where $\bar{Y}_{t}$, and $s_{D}$ are the mean and the standard deviation of $Y_{t}$ values, respectively.

Step 3: Separate the daily share returns $Y_{t}$ which have $Z_{t}$ values such that $Z<-2$ and $Z>2$ and assign them to "the class of high volatility, $C_{H V}$ ". Assign the other remaining $Y_{t}$ values to "the class of normal volatility, $C_{N V}$ ".

Step 4: Obtain the membership function of the class of high volatility, $C_{H V}$, via Eq.(8)

$$
\mu_{C_{H V}}=e^{-\frac{1}{2}\left(\frac{a-Y_{i}}{b}\right)^{2}}
$$

where $a=\left\{Y_{t} \in C_{H V} \mid \max \left(Y_{t}\right)\right\}$ and $b$ is the standard deviation of $Y_{t}$ values such that $Y_{t} \in C_{H V}$.

Evaluate the membership function of the class of normal volatility, $C_{N V}$, via Eq.(9)

$$
\mu_{C_{N V}}=e^{-\frac{1}{2}\left(\frac{Y_{i}-c}{d}\right)^{2}}
$$

where $c=\left\{Y_{t} \in C_{N V} \mid\right.$ mean $\left.\left(Y_{t}\right)\right\}$ and $d$ is the standard deviation of $Y_{t}$ values such that $Y_{t} \in C_{N V}$.

Step 5: Reassign each $Y_{t}$ to $C_{i}$ in which $\mu_{c_{i}}=\max \left(\mu_{C_{H V}}, \mu_{C_{N V}}\right)$

Step 6: Find the density of high activities by Eq.(10),

$$
p=\frac{n_{H V}}{n_{H V}+n_{N V}}
$$

where $n_{H V}$ and $n_{N V}$ are the number of $Y_{t}$ in the classes of $C_{H V}$ and $C_{N V}$, respectively.

Step 7: Take into account $s$ trading days,

- $\quad$ if the density of high activities in $s$ trading days, $p_{s}$, is greater than $p$, label these $s$ trading days as "the period with high volatility";

- $\quad$ if the density of high activities in $s$ trading days, $p_{s}$, is smaller than or equal $p$, label these $s$ trading days as "the period with normal volatility"

Repeat this step for next $s$ trading days.

For new observations, just only step 5 and step 7 may be applied for assignments and the other calculations and evaluations in other steps can be taken as constants. Or step 5-7 or whole algorithm can be processed, interactively.

\section{Application}

In this section, the offered fuzzy volatility labeling algorithm is applied on FTSE 100 index over the period of 20.08.2007-20.08.2012. In step 1, the daily share returns are obtained. The related descriptive statistics are calculated (Table 1). 
Table 1. Descriptive statistics of daily share returns

\begin{tabular}{lllll}
\hline Mean & Stdev & Median & Max & Min \\
\hline$-3.19451 \mathrm{E}-05$ & 0.015431 & 0.000227 & 0.093842 & -0.09265 \\
\hline
\end{tabular}

Source: authors

In step 2, the standardized values of daily share returns are calculated via $Z=\left(Y_{t}-(-0.0000319451)\right) / 0.015431$

In step 3, the daily share returns which have standardized values in the interval of $[-2,2]$ are stored in the class of normal volatility, $C_{N V}$; the other ones are stored in the class of high volatility, $C_{H V}$.

In step 4, the mean and the standard deviation of daily share returns in the class of normal volatility, $C_{N V}$, are calculated as 0.000199 and 0.011495 , respectively. The maximum value and the standard deviation of daily share returns in the class of high volatility, $C_{H V}$, are found as 0.093842 and 0.049178 , respectively. Via these values, the membership functions of classes are constructed as following,

$$
\mu_{C_{N V}}=e^{-\frac{1}{2}\left(\frac{Y_{i}-0.000199}{0.011495}\right)^{2}}, \mu_{C_{H V}}=e^{-\frac{1}{2}\left(\frac{0.093845-Y_{i}}{0.049178}\right)^{2}} .
$$

In step 5, each daily share return is reassigned to a class in which it has a greater membership degree, considering membership functions in step 4.

In step 6, it is determined that 138 daily share returns fall high volatility class. By using this value, the density of high activities is calculated as $p=138 / 1262=0.10935024$.

In Step 7, one month periods are taken as sub-periods and the density of high activities of each month is calculated. The periods which have a greater density value than 0.10935024 are labeled as "the period with high volatility". The remaining ones are labeled as "the period with normal volatility". The visual demonstration of this algorithm is given in Figure 2.

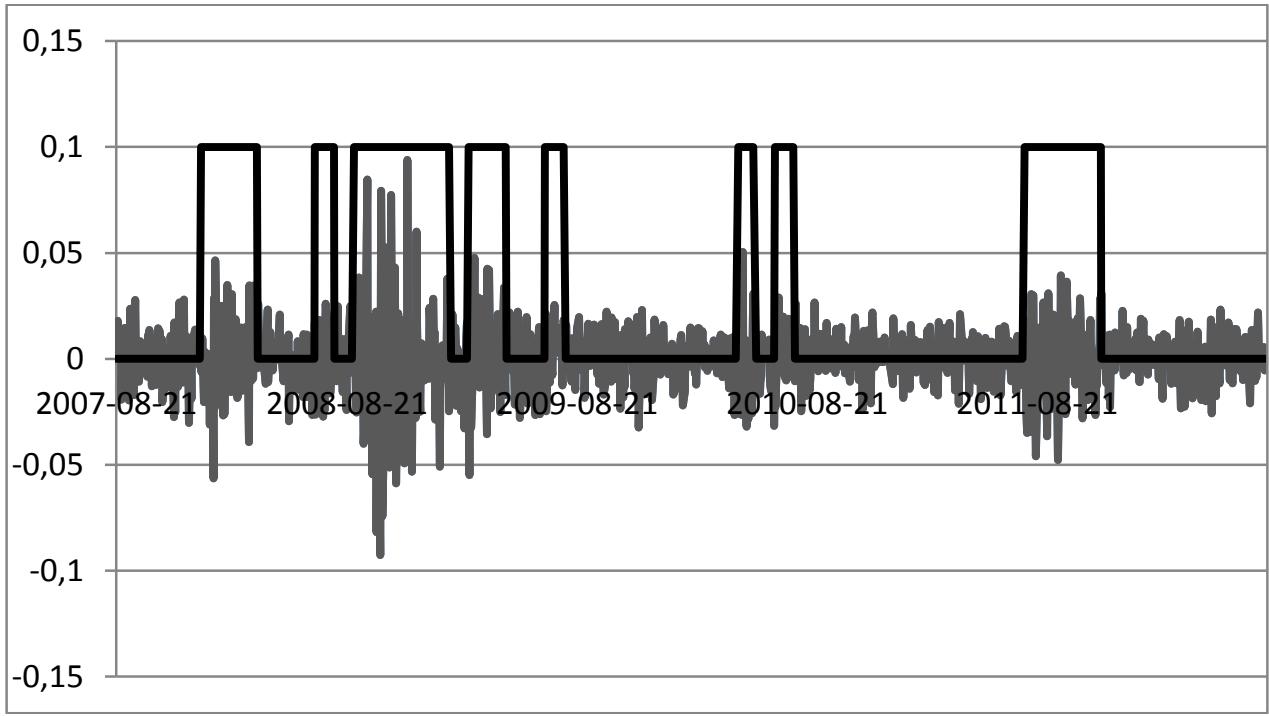

Fig. 2. The periods of FTSE 100 with normal and high volatilities

Source: authors

In Figure 2, the daily share returns are shown with grey lines. The labels of periods are shown with black lines. The black lines at the 0 value represent "the periods with normal volatility"; the black lines at the 0.1 value represent "the periods with high volatility". In the black lines, 0 and 0.1 values have not the mathematical meanings; they are just used arbitrarily for the visual representations of the periods of two different groups. 


\section{Conclusions}

In this paper, a fuzzy volatility labeling algorithm is offered to detect the abnormal activities in daily share returns. Considering vagueness in the switches of the states, fuzzy numbers are used for the evaluation of the classes of normal and abnormal activities of the daily share returns. In the generation of the membership functions of high and normal volatility classes, the descriptive statistics of daily share returns are used. Each daily share return is assigned to one of the classes by taking into account maximum membership degree. After all assignments, a common density of high activities is calculated. Then the time series is handled as sub-periods, and for each subperiod, the density of high activities is obtained. If it is greater than the common density of high activity, the related sub-period is labeled as "the period with high volatility"; if not, it is labeled as "the period with normal volatility".

The offered algorithm is applied on FTSE 100 index over the period of 20.08.2007-20.08.2012. The sub-periods with high and normal volatilities are detected. Accordingly, it is decided that 02.01.2008-31.03.2008, 01.07.200831.07.2008, 01.09.2008-30.01.2009, 02.03.2009-30.04.2009, 01.07.2009-31.07.2009, 04.05.2010-28.05.2010, 01.07.2010-30.07.2010, 01.08.2011-30.11.2011 sub-periods have high volatility.

The offered algorithm can be employed for sustainable risk management purposes.

\section{References}

Alaeddini, A.; Ghazanfari, M.; Nayeri, M.A. 2009. A hybrid fuzzy-statistical clustering approach for estimating the time of changes in fixed and variable sampling control charts, Information Sciences 179: 1769-1784.

Ang, K.K.; Quek C. 2012. Supervised Pseudo Self-Evolving Cerebellar algorithm for generating fuzzy membership functions, Expert Systems with Applications 39(3): 2279-2287.

Baikovs, A.; Zariņš, I. 2013. Philosophical, legal and general issues of legal liability, Entrepreneurship and Sustainability Issues 1(1): 2336. DOI: http://dx.doi.org/10.9770/jesi.2013.1.1(3)

Ban, A. 2008. Approximation of fuzzy numbers by trapezoidal fuzzy numbers preserving the expected interval, Fuzzy Sets and Systems 159(11): 1327-1344.

Bang, Y.K.; Lee, C.H. 2011. Fuzzy time series prediction using hierarchical clustering algorithms, Expert Systems with Applications 38: $4312-4325$.

Chen, S.M.; Tanuwijaya, K. 2011. Multivariate fuzzy forecasting based on fuzzy time series and automatic clustering techniques, Expert Systems with Applications 38(8): 10594-10605.

Cheng, C.H.; Cheng, G.V.; Wang, J.W. 2008. Multi-attribute fuzzy time series method based on fuzzy clustering, Expert Systems with Applications 3: 1235-1242.

D’Urso, P.; Cappelli, C; Lallo,D.D; Massari, R.2013. Clustering of financial time series, Physica A: Statistical Mechanics and its Applications 392 (9): 2114-2129.

D’Urso, P.; Maharaj, E.A. 2009. Autocorrelation-based fuzzy clustering of time series, Fuzzy Sets and Systems 160: 3565-3589.

Garškaitè-Milvydienè, K. 2014. Anti-crisis management of enterprises and possibilities of overcoming their critical condition, Entrepreneurship and Sustainability Issues 1(4): 187-203. DOI: http://dx.doi.org/10.9770/jesi.2014.1.4(1)

Litvaj, I.; Poniščiaková, O. 2014. Entrepreneurship and quality management, Entrepreneurship and Sustainability Issues 1(4): $204-209$. DOI: http://dx.doi.org/10.9770/jesi.2014.1.4(2)

Figurska, I. 2014. Sustainable entrepreneurship: localization, acquiring and use of knowledge sources in competitive organization, Entrepreneurship and Sustainability Issues 1(4): 210-222. DOI: http://dx.doi.org/10.9770/jesi.2014.1.4(3)

Šabasevičienė, V.; Grybaite, V. 2014. Main foreign direct investment factors as precondition of sustainable entrepreneurship: evidence from Lithuania, Central and Eastern Europe, Entrepreneurship and Sustainability Issues 1(4): 230-238. DOI: http://dx.doi.org/10.9770/jesi.2014.1.4(5)

Dzemyda, I.; Raudeliūnienè, J. 2014. Sustainable youth entrepreneurship in conditions of global economy toward energy security, Entrepreneurship and Sustainability Issues 1(4): 247-256. DOI: http://dx.doi.org/10.9770/jesi.2014.1.4(7) 
Grzegorzewski, P. 2008. Trapezoidal approximations of fuzzy numbers preserving the expected interval -Algorithms and properties, Fuzzy Sets and Systems 159 (11): 1354-1364.

Lai, C.P.; Chung, P.C.; Tseng, V.S. A. 2010. Novel two-level clustering method for time series data analysis, Expert Systems with Applications 37: 6319-6326.

Laužikas, M.; Krasauskas, A. 2013. Impacts of sustainable structural growth on the economic performance of listed companies, Entrepreneurship and Sustainability Issues 1(2): 81-91. DOI: http://dx.doi.org/10.9770/jesi.2013.1.2(2)

Laužikas, M.; Mokšeckienè. 2013. The role of creativity in sustainable business, Entrepreneurship and Sustainability Issues 1(1): 10-

22. DOI: http://dx.doi.org/10.9770/jesi.2013.1(2)

Lee, C.H.; Pan, H.Y. 2009. Performance enhancement for neural fuzzy systems using asymmetric membership functions, Fuzzy Sets and Systems 160(7): 949-971.

Liao, T.W. 2007. A clustering procedure for exploratory mining of vector time series, Pattern Recognition 40(9): 2550-2562.

Maharaj, E.A.; D’Urso, P. 2011. Fuzzy clustering of time series in the frequency domain, Information Sciences 181: 1187-1211.

Nasibov, E.N.; Peker, S. 2011. Time series labeling algorithms based on the K-nearest neighbors' frequencies, Expert Systems with Applications 38: 5028-5035.

Rodpongpun, S. V. Niennattrakul, C.A. 2012. Ratanamahatana. 2012. Selective Subsequence Time Series clustering, Knowledge-Based Systems 35: 361-368.

Šimelytė, A.; Antanavičienè, J. 2013. Economic development and its influence on state capital structure, Entrepreneurship and Sustainability Issues 1(1): 1-9. DOI: http://dx.doi.org/10.9770/jesi.2013.1(1)

Tvaronavičienè, M. 2014. If industrial sector development is sustainable: Lithuania compared to the EU, Entrepreneurship and Sustainability Issues 1(3):134-142. DOI: http://dx.doi.org/10.9770/jesi.2014.1.3(2)

Wahl, M.; Prause, G. 2013. Toward understanding resources, competencies, and capabilities: business model generation approach, Entrepreneurship and Sustainability Issues 1(2): 67-80. DOI: http://dx.doi.org/10.9770/jesi.2013.1.2(1)

Zadeh, L.A. 1965. Fuzzy sets, Inform and Control 8: 338-353.

Zhang, X.; Liu, J.; Du, Y.; Lv, T. 2011.A novel clustering method on time series data, Expert Systems with Applications 38: 1189111900 .

Sinem PEKER - Dr. Assist. Professor at Yasar University, Department of Statistics. She obtained her both MSc and PhD degrees from Dokuz Eylul University in Turkey. Her research interests focus mainly on Data analysis, Fuzzy logic, Data mining, Clustering.

Manuela TVARONAVIČIENĖ - Dr., full professor at Vilnius Gediminas Technical University, Business Management Faculty and full professor at The General Jonas Žemaitis Military Academy of Lithuania; member of editorial boards of peer-reviewed international scientific journals, expert of the Research Council of Lithuania, head and member of scientific projects. She is alumnus of IESE Business School; raised qualifications at Harvard Business School (USA) and Cambridge University, Judge School (UK). She is author of more than 60 papers. Research interests: economic growth, sustainable development, innovations, investments, energy security, entrepreneurship.

Bora AKTAN - Dr., Assist. Professor of Finance, College of Business Administration, University of Bahrain. His current research activity focuses on emerging capital markets, global investments particularly in real estate investment trusts, financial time-series analysis, volatility modelling-forecasting and energy issues. He has published in different refereed journals such as International Journal of Forecasting, European Journal of Finance, International Journal of Business, Journal of Property Investment and Finance. Dr. Aktan is a member of some professional bodies such as The International Institute of Forecasters (IIF), Society for the Study of Emerging Markets (SSEM), The Society for Financial Econometrics (SOFIE), among others. Dr. Aktan also serves EuroMed Research Business Institute as a Research Fellow at the Asset Management and Emerging Markets Groups. 